\title{
IDEAS POLÍTICAS EN ALGUNAS OBRAS LEXICOGRÁFICAS MONOLINGÜES DEL SIGLO XIX: EN TORNO A LO LIBERAL Y LO NACIONAL*
}

\author{
THE TREATMENT OF POLITICAL LEXICAL ITEMS IN SOME MONOLINGUAL \\ DICTIONARIES OF THE 19TH CENTURY: ON LIBERAL AND NATIONAL IDEAS
}

\author{
Matthias RAaB \\ Universitat de Barcelona \\ raab@ub.edu
}

Recibido: $14 / 02 / 2019$

Aceptado: 15/04/2019

\section{Resumen}

En el presente trabajo, se estudia el tratamiento lexicográfico que reciben las voces relativas a las ideas políticas incipientes del liberalismo y nacionalismo a lo largo del siglo XIX. Para ello, se rastrearán los cambios destacados en los artículos lexicográficos correspondientes a los términos liberal, libertad y liberalismo, por un lado; y nación, nacional, nacionalidad y nacionalismo, por otro, teniendo en cuenta tanto las obras lexicográficas de la Real Academia Española como los diccionarios no académicos más sobresalientes que se publicaron a mediados del siglo. El trabajo evidencia el distinto tratamiento de las voces en obras académicas y no académicas y confirma la periodización de los diccionarios académicos decimonónicos propuesta.

\begin{abstract}
This paper aims to study the lexicographical treatment received by the lexical items related to the incipient political ideas of liberalism and nationalism throughout the 19th century. The highlighted changes in the lexicographical articles of the terms liberal, libertad and liberalismo will be traced on the one hand, and nación, nacional, nacionalidad y nacionalismo on the other. Both the dictionaries of the Real Academia Española and the most outstanding nonacademic dictionaries that were published in the middle of century, will be taken into account. The work evidences the different treatment of the voices in academic and non-academic works and confirms the proposed periodization of the nineteenth-century academic dictionaries.
\end{abstract}

\footnotetext{
* Esta investigación ha sido posible gracias a la ayuda de la DIGICYT para el proyecto "Historia interna del Diccionario de la lengua castellana de la Real Academia Española en el siglo XIX (1817-1852)" ( $\mathrm{n}^{\circ}$ de referencia FFI2014-51904-P) y al apoyo del Comissionat per Universitats $i$ Recerca de la Generalitat de concedido al "Grupo de Lexicografía y Diacronía" ( ${ }^{\circ}$ de referencia 2014 SGR1328).
}

Para citar este artículo / To cite this article: Raab, Matthias. Ideas políticas en algunas obras lexicográficas del siglo XIX: en torno a lo liberal y lo nacional. Azorín, Dolores; Clavería, Gloria y Jiménez Ríos, Enrique (Eds.): ELUA: El diccionario de la Academia y su tiempo: lexicografía, lengua y sociedad en la primera mitad del siglo XIX, Anexo V, págs. 89-106.

Enlace/Link: http://dx.doi.org/10.14198/ELUA2019.ANEXO5.05 
PALABRAS CLAVE: lexicografía, siglo XIX, historiografía, ideas políticas, ideología
KEY WORDS: lexicography, 19th century, historiography, political ideas, ideology

\section{INTRODUCCIÓN}

Los diccionarios no solo poseen su propia ideología lingüística implícita, que se ha estudiado entre otros en Quilis (2008) o Lleal (2015), sino que además ostentan un valor pedagógico que radica en "difundir aquellos conocimientos que, en cada momento histórico, vinculan a una comunidad lingüística determinada con su entorno cultural inmediato" (Azorín 1992: 448). Partiendo de esta premisa, pretendemos profundizar en estas páginas en el estudio del tratamiento lexicográfico que los diccionarios decimonónicos de la Real Academia Española, por un lado, y las obras que se confeccionaron fuera del ámbito de la Academia en la corriente conocida como lexicografía no académica (Seco 1987: 129), por otro, brindaron a dos campos conceptuales tan sumamente ideologizadas en la época, como son los conceptos sociopolíticos de la libertad y la nación.

Para ello, situaremos el nacimiento de las ideas de lo liberal y lo nacional en su debido contexto histórico (2.) y trataremos de relacionar esta historia externa con la historia interna de la lexicografía decimonónica (3.), tanto en su vertiente académica (3.1.) como extraacadémica (3.2.), donde merecen especial atención las obras de Salvá (1846) (3.1.1.) y Domínguez (1846-47) (3.1.2.). A continuación, procederemos al análisis per se de las entradas correspondientes a los dos campos ideológicos -libertad, liberal y liberalismo, por un lado; y nación, nacional, nacionalidad y nacionalismo, por el otro--, que se ha efectuado a partir de los datos extraídos del Nuevo Tesoro Lexicográfico de la Lengua Española (NTLLE) (4.). Finalmente, unas breves conclusiones (5.) cerrarán el presente estudio.

\section{LAS PREOCUPACIONES HISTÓRICAS Y SOCIOPOLÍTICAS DE LA PRIME- RA MITAD DEL SIGLO XIX}

Difícilmente podría imaginarse una época más convulsa que la de la Europa del siglo XIX. Como parte de ella, España sufrió las tres Guerras Carlistas (1833-1840, 1846-1849 y 1872-1876), la crisis del Antiguo Régimen y la Guerra de la Independencia (1808-1814). En plena guerra, se constituyeron y celebraron las Cortes de Cádiz (1810-1814), donde se votó y aprobó en 1812 la Constitución de Cádiz, conocida como La Pepa, cuya consecuencia fue la contrarrevolución del reinado absolutista de Fernando VII (1814-1820 y 1823-1833), impulsado por los detractores de las ideas liberales incluidas en la Constitución. La última etapa del reinado de Fernando VII, que empezó con el sometimiento de las fuerzas liberales y el final del Trienio Liberal en 1823, se conoce como la Década Ominosa. La época del reinado de Isabel II (1833-1868) es conocida por la apertura paulatina a las ideas liberales. Esta liberalización culminó en la Revolución Liberal de 1868, el Sexenio Democrático (1868-1874) y la Primera República española (1873-1874), que se convirtió en la Dictadura de Serrano y fue seguida por la Restauración borbónica (a partir de 1874). Las secuelas del final del Imperio Español, el llamado desastre del 98, además, se vivieron durante el primer tercio del siglo siguiente'.

1 Véase, acerca de los acontecimientos del siglo XIX desde un punto de vista histórico, a Álvarez Junco (2001), Carr (1988) o Fusi y Palafox (1997) y, más concretamente sobre la época del liberalismo, el monográfico dirigido por Fontana y Villares (2007). 
Solo puede entenderse tal sucesión rápida de acontecimientos históricos, bélicos y revolucionarios teniendo en cuenta la proximidad tanto cronológica como geográfica de la Revolución Francesa de 1789. La Declaración de los derechos del hombre y del ciudadano de agosto de 1789 -y la Declaración de los derechos de la mujer y la ciudadana de 1791- no solo forman parte, aunque con modificaciones menores, de todas las Constituciones francesas aprobadas desde el año de la Revolución, sino que sus contenidos universales acerca de la libertad, la propiedad, la seguridad y la resistencia a la opresión tuvieron repercusiones profundas en el resto del continente y España, donde la lucha entre reformadores liberales y defensores partidarios del régimen actual tendría gran protagonismo durante toda la centuria posterior, de modo que la Revolución supuso "un tajo decisivo entre lo que a partir de entonces se llamaría, muy justamente, el Antiguo Régimen y el nuevo orden político y social que pretendió crearse sobre fundamentos enteramente nuevos" (García de Enterría 2001: 18)².

Por lo que respecta al nacimiento del movimiento nacionalista en España, hay que establecer un vínculo estrecho -según la opinión de los historiadores expertos de la época- entre esta ideología y el liberalismo de las Cortes de Cádiz. Así afirma Álvarez Junco (2001: 129) ${ }^{3}$ :

A partir de 1808 puede hablarse en España de nacionalismo: el patriotismo étnico pasó a ser plenamente nacional, al menos entre las élites. Y ello fue obra indiscutible de los liberales. Las élites modernizadoras aprovecharon la ocasión para intentar imponer un programa de cambios sociales y políticos; y el método fue lanzar la idea revolucionaria de la nación como titular de la soberanía. El mito nacional resultó movilizador contra un ejército extranjero y contra los colaboradores de José Bonaparte, en tanto que no españoles (afrancesados). Los liberales españoles recurrieron a la identificación entre patriotismo y defensa de la libertad: como declaró el diputado asturiano Agustín Argüelles al presentar la Constitución de 1812, "españoles, ya tenéis patria".

\section{HISTORIA LEXICOGRÁFICA DEL SIGLO XIX}

Podría pensarse que la Real Academia Española, en cuanto institución cuyo interés principal consiste en el cuidado de la lengua española, no se vio afectada por las corrientes políticas contemporáneas.

Sin embargo, en los Diarios de sesiones de las Cortes Generales y Extraordinarias (24 de septiembre a 20 de septiembre de 1813), que fueron estudiados en profundidad por Battaner $(2008 ; 2009)$ en cuanto a la presencia de la lengua y la reflexión sobre las lenguas, y la mera inclusión de debates sobre la constitucionalización de la Real Academia Española (2009: 42) en las Cortes constituyentes dejan patente que no es preciso hablar de la Academia como de una institución enteramente apolítica o, al menos, una institución ajena a toda influencia política.

Es más, incluso hubo académicos que participaron activamente en las Cortes gaditanas (cfr. Clavería 2018: 17; Battaner 2008; García de la Concha 2014: 154-156 o Merino 2013: 82). También Zamora (1999: 451), quien parte de la documentación interna de la Academia, describe la represión absolutista contra académicos liberales y afrancesados.

En la misma línea, detalla Clavería (2018: 17) que

2 Las consecuencias de la Revolución para España se detallan en Cornide Ferrant (2003).

3 Acerca del nacionalismo y los nacionalismos en España, consúltese a Linz (1991) o Núñez Seixas (1993). 
Con el fin de la guerra y el regreso de Fernando VII, la Academia despierta del forzoso letargo y reemprende los trabajos propios de su oficio, que darán como resultados inmediatos la publicación de la octava edición de la ortografía en 1815 y de la quinta edición del diccionario en 1817. Los cambios que sufre, en especial en 1814, serán fiel reflejo y consecuencia de la situación que se vivió.

Los cambios que sufre en 1814 se refieren a "una notable renovación en el elenco de miembros" (ibid.) que también afectó a la cúpula de la Academia. Así, el director elegido en la primavera de 1814, Ramón Cabrera, "fue fulminantemente destituido por orden del rey" (ibid.: 18; cfr. también García de la Concha 2014: 140-164 y Zamora 1999: 224). El sucesor y director de la RAE de 1814 a 1828, Miguel José de Carvajal, fue a la vez ministro y consejero de Estado bajo las órdenes de Fernando VII.

$\mathrm{Y}$ es por hechos como los descritos por los que cobran tanta validez y tanto interés las reflexiones de Nierderehe (2001: 192 [apud Battaner 2009: 44]) sobre la historia de la lingüística, que nos permitimos trasladar a la historia de los diccionarios y el tratamiento lexicográfico de las voces:

[...] querría llamar la atención al hecho de que la historia de la lingüística de una época no se escribe exhaustivamente al hablar solo de las influencias de tal escuela sobre otra o de la dependencia de tal maestro de gramática de otro colega, sino que -de vez en cuando, por lo menos- hay que hacer referencia también al contexto social en que nacen las obras estudiadas.

\subsection{La lexicografía académica del siglo XIX}

Siguiendo las palabras de Niederehe, los hechos detallados arriba y que marcan un hiato en la historia de la Academia en el año 1814 coinciden con la periodización de la lexicografía académica del siglo XIX establecida por Clavería (2016: 251-252 y 2018: 16) y defendida por Blecua (2018: 10). Y es que la primera edición del siglo XIX, la 4. ${ }^{\text {a }}$ edición de 1803, sería la última de la primera serie de diccionarios académicos, que se caracterizan en su conjunto por su fuerte dependencia del Diccionario de autoridades (1726-1739) y el afán de los lexicógrafos de revisar esta primera obra lexicográfica de la Academia.

Por consiguiente, la cesura que se produjo en los hechos históricos acontecidos entre la 4. ${ }^{\mathrm{a}}$ y la 5. ${ }^{\mathrm{a}}$ edición de 1817 se corresponde con el nacimiento de un nuevo período lexicográfico, como detalla Clavería (2016: 252):

La edición de 1817, muy posiblemente por las excepcionales circunstancias externas en las que se desarrolló (especialmente los años 1808-1814), se configura como una edición en la que se produce una ruptura con [la] metodología lexicográfica aplicada hasta el momento.

Por lo que se refiere a la producción lexicográfica a partir de la 5. a edición de 1817 , la propuesta de Clavería postula la existencia de dos fases durante la centuria estudiada, que comprenden, por un lado, las ediciones 5. ${ }^{\mathrm{a}}$ (1817), 6. ${ }^{\mathrm{a}}(1822)$, . $^{\mathrm{a}}(1823), 8 .^{\mathrm{a}}$ (1837), 9. ${ }^{\mathrm{a}}$ (1843) y $10 .^{\mathrm{a}}$ (1852) del $D R A E$; y las tres ediciones restantes $(1869,1884$ y 1899), por otro.

La segunda cesura -en cuanto a las labores lexicográficas se refiere- se produce entre las ediciones $10 .^{\mathrm{a}}$ y $11 .^{\mathrm{a}}$ (1852 y 1869 , respectivamente), un período en que, por un lado, se 
consolida el poder de las fuerzas liberales bajo el reinado de Isabel II y ganan las fuerzas revolucionarias de la Revolución liberal de 1868; y, por otro, se abren terreno los grandes diccionarios no académicos de mediados del siglo XIX (véase 3.2). Clavería (2016: 252) atribuye esa nueva fase de los diccionarios académicos exclusivamente a aspectos lexicográficos ajenos a la historia exterior a la Academia:

Las tres últimas ediciones del siglo deben ser contempladas como fases de un mismo proceso por lo que entre ellas existe una continuidad a la vez que una evolución de objetivos y son fruto de todos los cambios en las tareas lexicográficas que pone en práctica la Academia en la segunda mitad del siglo XIX. La undécima edición (RAE 1869) sirve como punto de partida, la edición siguiente (RAE 1884) significa la consolidación del cambio tanto en la faceta lexicográfica como en la lexicológica; en la última edición del siglo (RAE 1899) arraigan los presupuestos teórico-prácticos de la edición anterior a la vez que se emprenden nuevos caminos en el quehacer lexicográfico.

Por otro lado, la misma RAE da cuenta en la introducción “Al Lector" del DRAE 1869 de la presencia de quejas y peticiones ajenas a la Academia, por lo que al aumento de voces en general se refiere:

Así es que, desatendiendo el vulgar clamoreo de los que miden la riqueza de una lengua por el número de vocablos, sean ó no necesarios, estén ó no estén analógicamente formados, ofrezcan ó no prendas de duración, se ha mantenido firme en su decisión de no sancionar más palabras nuevas que las indispensables, de recta formación, é incorporadas en el Castellano por el uso de las personas doctas.

En cuanto a las voces del ámbito ideológico-político, concluye Moreno (2008: 479-480) en un estudio sobre el tratamiento del vocabulario de los primeros liberales en la lexicografía académica decimonónica que

como era de esperar dado el criterio conservador que rige a dicha institución, la Academia no registra el uso consolidado de las voces seleccionados ampliamente documentados, en los diccionarios académicos no se recogen o se recogen sólo muy tardíamente. Ejemplo de ello serán especialmente las ediciones de 1869 y 1884, en donde, a pesar del fuerte inmovilismo y rechazo a incluir referencias políticas, hallamos que la Academia da paso paulatinamente a nuevos significados relacionados con este campo temático de manera cada vez más frecuente.

En esta misma línea, observa Fernández Sebastián (2009: 703) que

los lexicógrafos, siempre cautelosos, de la Real Academia española admiten por fin en la edición del 1852 del Diccionario oficial la voz liberal en su sentido político [...]. Cuatro décadas había tardado esta palabra en ascender desde su acuñación popular en el Cádiz de las Cortes al registro académico, y todavía algunos años más tardaría en aparecer en el DRAE -ismo correspondiente [...].

4 No se recogen observaciones sobre la lexicografía no académica en las entradas correspondientes a nación y liberalismo de esta obra de corte historiadora. 
En resumen, entre las observaciones de Moreno y Clavería ${ }^{5}$, por un lado, y las explicaciones preliminares de la Academia en el $D R A E$ 1869, por otro, se refleja cierta pugna entre inmovilismo e innovación que parece apoderarse de los lexicógrafos académicos a partir de la duodécima edición y cuyo resultado en cuanto al tratamiento del vocabulario de las corrientes políticas del siglo XIX examinaremos en estas páginas.

\subsection{La lexicografía no académica del siglo XIX}

En palabras de Quilis Merín (2016: 51), la centuria estudiada “constituye uno de los espacios privilegiados por la investigación historiográfica que ha propiciado un exhaustivo conocimiento de la actividad lexicográfica de la Academia"; y sin duda, se trata del Siglo de Oro de la lexicografía española, también porque otro aspecto fundamental de la lexicografía decimonónica radica en el final del monopolio lexicográfico de la Real Academia Española.

Aunque con Terreros y Pando (1786-1793) ya había aparecido el primer gran diccionario no académico a finales del siglo XVIII, este, tal y como señala García Platero (2003: 265), "no obtuvo la repercusión debida, dado que vio la luz en una época en la que el Diccionario de autoridades suscitó todo el interés."

En cambio, la lexicografía no académica -término acuñado por Seco (1987: 129)-, sobre todo aquellos diccionarios que se publicaron a mediados del siglo XIX nacieron con "una innegable concepción totalizadora" e intentaron "abarcar la realidad lingüística y extralingüística" (García Platero 2003: 267), "pretendían ser diferentes" (Vázquez 2006: 43) y, efectivamente, lograron diferenciarse de las obras académicas contemporáneas por su forma enciclopédica (cfr. Azorín 1996-97 o Martínez Marín 2000).

Como en el caso de la lexicografía académica, la época histórica dejó huellas profundas en las obras no académicas. Así afirma Henríquez Salido (2009: 362-363) que

No es casual que, a pesar de la agitación existente en España desde 1808 a 1814 y las continuas convulsiones sociales [...] se produzca desde 1825 hasta 1853 una eclosión de diccionarios generales no académicos, como el de Manuel Núñez de Taboada (1825), el de Vicente Salvá (1846), el de Adolfo de Castro y Rossi (1852) o el de Ramón Joaquín Domínguez (1853). Estos diccionarios seleccionan el ennoblecido léxico revolucionario, incorporan nuevos 'sentidos' a los vocablos e incluyen nuevos lemas, con el propósito de informar a los usuarios sobre las palabras clave del nuevo sistema político.

De entre estas obras del "movimiento extra-académico" (Azorín 2000: 229), conviene destacar el Nuevo diccionario de la lengua castellana (Salvá 1846) y el Diccionario nacional o gran diccionario clásico de la lengua española (Domínguez 1846-47), ambos miembros de la "generación lexicográfica del 1850" (Quilis Merín 2016: 51) de pensamiento liberal y posteriormente progresista. Ahora bien, a pesar de los posicionamientos

5 Sobre la lexicografía académica del siglo XIX, consúltese la larga lista de referencias bibliográficas que se recoge en Clavería y Freixas (2018: 543-570) y también en la página web del proyecto de investigación "Historia interna del Diccionario de la lengua castellana de la Real Academia Española en el siglo XIX (1817-1852)" [FFI2014-51904-P], http://draesxix.wixsite.com/draesxix.

6 Acerca de Terreros y Pando, véase también a Alvar Ezquerra (1987 [2002] y 2002), Carvajal (1988). Álvarez de Miranda (1992), Jiménez Ríos (1996), Azorín y Santamaría (2004), Azorín (2009), Clavería (2010) o Raab (2018). 
ideológicos compartidos entre los dos lexicógrafos, los respectivos modi operandi -la técnica lexicográfica- del Adicionador por un lado y Domínguez por otro, no podrían ser más distintas.

Así, Salvá (1846) en la "Introducción del Adicionador" (pág. XIV) defiende la neutralidad ideológica más absoluta como una necesidad lexicográfica:

un lexicógrafo nunca debe manifestar sus propensiones ni su modo de pensar en materias políticas y religiosas, ni ménos ridiculizar ó condenar como errores las doctrinas que siguen varones muy doctos, un gran número de personas de naciones ilustradas y la mayoría de algunas muy cultas.

E ilustra sus palabras a través del siguiente ejemplo:

Le incumbe solo definir á Predamita y Selenita de modo que pueda entenderse con claridad lo que significan estos nombres, cuando se encuentran en los libros que impugnan ó sostienen su existencia, ó se mencionan por incidente ó por hipótesis; sin extenderse nunca á calificar de erróneos los sistemas que hay ó ha habido sobre el particular.

Y, finalmente, sentencia: "Este es el mejor medio para que sea leído por un largo período y por personas de todos los países y de diversas opiniones, y el mas seguro para no equivocarse."

A pesar de estas afirmaciones, no se debe olvidar que Salvá se vio obligado a exiliarse y vivió tanto en Londres como en París, donde finalmente se publicó el Nuevo Diccionario, después de la restauración de la monarquía absolutista en la persona de Fernando VII ${ }^{7}$.

Como Vicente Salvá, Ramón Joaquín Domínguez, el autor del Diccionario nacional o gran diccionario clásico de la lengua española (1846-47), se exilió en Francia por sus ideas revolucionarias y progresistas, pero, al contrario de Salvá, "es un fiel representante del carácter apasionado, esencialmente romántico, de unos hombres que reflejaron en su obra toda su actividad y compromiso social y político" (García Platero 2003: 271; cfr. también Seco 1987: 168-177). Y cierto es que el estilo del breve prólogo a su obra -con alusión política incluida- deja entrever cierto espíritu revolucionario:

Así es, que no hay un solo hombre pensador que se satisfaga con el fruto del estudio de los antiguos, y que no se crea con el derecho, y aun con el deber, de dar un impulso á aquello á que se dedica. Hace esperimentos, inventa máquinas, baja hasta las entrañas de la tierra á arrancar de su seno un tesoro desconocido á sus abuelos; se remonta á los astros, en los que descubre una nueva circunstancia que utiliza para cultivar con oportunidad la tierra que domina; trastorna los estados, dándoles una nueva forma de gobierno; altera su mismo idioma, y finalmente, nada hay en toda la naturaleza que no se resienta de la mano del hombre. [la negrita es nuestra]

Efectivamente, Anglada y Bargalló (1992: 960) afirman que Domínguez representa "la superación del hiato que en el siglo XIX existía entra la actividad lexicográfica académica y el progreso social"; y Moreno (2008: 480) le atribuye una "postura [...] comprometida

7 cfr. Azorín Fernández 2000 o, para la bibliografía completa del autor valenciano, Reig Salvá 1972. Otros estudios sobre el autor y su Nuevo Diccionario ofrecen Álvarez de Miranda (2002 y 2003), Azorín y Baquero (1994-95) o Azorín (2001 y 2003). 
ideológicamente". Seco (1983) le dedica incluso un estudio llamado "La definición lexicográfica subjetiva: el Diccionario de Domínguez" y lo convierte, de esta manera, en el prototipo de la subjetividad lexicográfica.

Fiel reflejo de estas afirmaciones son algunas alusiones poco disimuladas hacia la Academia y que se encuentran en varias definiciones de voces de carácter claramente político del diccionario de Domínguez (recuérdese aquí la referencia al vulgar clamoreo del Prólogo de la 11. a edición del $D R A E$ citada en 3.1.). Así, añade la acepción 'Alzamiento ó movimiento insurreccional, voz últimamente usada en España para designar con ella todos los movimientos que han ocurrido de pocos años á esta parte, y que la Academia no admite.' (Domínguez 1846-47, s. v. pronunciamiento) [la negrita es nuestra] a la voz pronunciamiento y da así entrada a hechos históricos como El Pronunciamiento de Riego, que restituyó la Constitución de Cádiz en 1820 y dio paso al Trienio Liberal:

Pronunciamiento, s. m.

Alzamiento ó movimiento insurreccional, voz últimamente usada en España para designar con ellas todos los movimientos que han ocurrido de pocos años á esta parte, y que la Academia no admite. || Publicación de un fallo.

Un segundo artículo muy ilustrativo en este sentido, lo constituye la voz progresista. Por un lado, Domínguez es el primer lexicógrafo en dar entrada a esta voz en el volumen II de su diccionario (1847), lo cual ya atribuye un valor especial a este término por el hecho en sí. Por otro, el artículo contiene una defensa incondicional y casi a ultranza de todos los progresistas, ya que define al progresista como 'Partidario del progreso ó de la causa de las reformas que marcha siempre en sostén de los adelantos de la civilización y de la realización de las mejoras que según sus necesidades van reclamando los pueblos' (Domínguez 1846-47, s. v. progresista). Y, acto seguido, lanza un dardo envenenado hacia la Academia: "Esta palabra ha hecho sin duda asco á la Academia, que no se ha dignado recibirla como española, cuando nuestro país es el único en que se da esta denominación á los liberales avanzados, no pudiéndose decir que ha sido importada del estrangero."

\section{Progresista, s.}

Partidario del progreso ó de la causa de las reformas que marcha siempre en sostén de los adelantos de la civilizacion y de la realizacion de las mejoras que segun sus necesidades van reclamando los pueblos. Esta palabra ha hecho sin duda asco á la Academia, que no se ha dignado recibirla como española, cuando nuestro país es el único en que se da esta denominacion á los liberales avanzados, no pudiéndose decir que ha sido importada del estrangero.

Por último, la opinión de Domínguez sobre corrientes menos progresistas del liberalismo, llamadas moderadas, queda patente en el artículo correspondiente a la voz moderantismo (Domínguez 1846-47, s. v. moderantismo):

Moderantismo, s. m.

Polít. Doctrina ú opinion política, cuyos principios estan fundados en una moderacion circunstancial é indeterminada, elástica segun las necesidades y exigencias de la situacion. Sus sectarios constituyen una asociación parásita, que solamente puede existir entre azares y sufriendo los encontrados embates del absolutismo y de la libertad. 
Más allá de la ideología claramente republicana de Domínguez frente a la aparente neutralidad ideológica de las obras académicas, más cercanas al statu quo (y, por tanto, también ideológicas), concluye Gutiérrez Cuadrado (2011: 64), desde un punto de vista metalexicográfico, que "tan poco neutro ideológicamente como el de Domínguez era el diccionario académico de aquellos años [...], pero que, al contrario de Domínguez, "aceptaba la normalización lexicográfica. [...] Las definiciones del Diccionario académico son tan generales que, en realidad, dejan sin definir el definido. Las de Domínguez intentan definir de acuerdo con la realidad histórica del momento el sentido del definido."

Se trata, en definitiva, de una obra que "destaca entre las demás de su siglo tanto por la expresión de las ideas del compromiso político y social de su autor, como por la peculiar presencia del enunciador en el texto de la definición" (Quilis Merín 2014: 142-143).

\section{EL TRATAMIENTO DE VOCES POLÍTICAS EN LA LEXICOGRAFÍA DEL SIGLO XIX}

\subsection{EI tratamiento de las voces liberal, libertad y liberalismo en la lexicografía decimo- nónica}

En la 4. a edición del Diccionario de la lengua castellana (1803), la entrada libertad mantiene -aparte de los cambios microestructurales bien conocidos- las acepciones recogidas desde el Diccionario de autoridades, con la excepción de la acepción 5, "Hablando de un estado, ó de un pais, es la forma del gobierno aristocrático, ó democrático", (DRAE 1803, s. v. libertad), que es justo la que es objeto de nuestro estudio:

LIBERTAD. s.f. La facultad de obrar, ó no obrar, por la qual se dice que tenemos alguna cosa en nuestra mano, ó que somos dueños de nuestras acciones. Libertas, libera voluntas. LIBERTAD. El estado y condicion del que no es esclavo. Libertas.

LIBERTAD. El estado del que no está preso. Libertas.

LIBERTAD. La falta de sujecion y subordinacion: y así se dice: que á los jóvenes les pierde la LIBERTAD. Licentia.

LIBERTAD. Hablando de un estado, ó de un pais, es la forma del gobierno aristocrático, o democrático. Libertas.

Por lo que se refiere al artículo correspondiente al adjetivo liberal, en cuanto a sus acepciones no dista de los sentidos propuestos y recogidos desde Autoridades, ninguna de ellas referida al pensamiento político (DRAE 1803, s. v. liberal):

LIBERAL. adj. El que obra con liberalidad, ó la cosa hecha con ella. Liberalis, munificus. LIBERAL. Expedito, pronto para executar qualquiera cosa. Liberalis, expeditus.

LIBERAL. Se dice del arte propia del ingenio á diferencia de la mecánica.

De hecho, no es hasta la $10 .^{a}$ edición del $D R A E$ (1852) que aparece una cuarta acepción que, por primera vez en la lexicografía académica, hace referencia al liberalismo político y a "El que profesa doctrinas favorables a la libertad política de los estados" (DRAE 1852, s. v. liberal) que había llevado a la redacción y aprobación de la Constitución de Cádiz justo 40 años antes. 
LIBERAL. adj. El que obra con liberalidad, ó la cosa hecha con ella. Liberalis, munificus || Expedito, pronto para ejecutar cualquiera cosa. Expeditus, promtus, strenuus. Se dice del arte propia del ingenio á diferencia de la mecánica. Liberalis. \| El que profesa doctrinas favorables á la libertad política de los estados.

Dicha acepción, nueva por lo que a las obras académicas se refiere, se parece al sentido neológico que recoge Salvá (1846, s. v. liberal) seis años antes:

[|| neol. El que tiene ideas favorables á la justa libertad del pueblo.]

Ahora bien, solo aparece el término que designa al movimiento político liberal, liberalismo, en Domínguez (1846-47, s. v. liberalismo), quien, sui generis, define la ideología no solo como la 'cualidad de lo liberal', sino, en su primera acepción, como el 'Amor á la libertad'. Gracias a la presencia de la marca lexicográfica Polit., que introduce la acepción, queda patente la lectura ideológico-política subjetiva de Domínguez.

Liberalismo, s. m. V. Liberalidad. || Polít. Amor á la libertad; cualidad de lo liberal. ${ }^{8}$

Es consecuente esta definición con la última acepción del adjetivo liberal en la misma obra (ibid., s. v. liberal), y también acompañada de la etiqueta Polit.:

Liberal, adj. Polit. Amante de la libertad, enemigo de la tiranía; mas ó menos demócrata.

La primera definición menos connotada de liberalismo aparece, finalmente, en el diccionario de Gaspar y Roig (1855), donde se define de la siguiente manera:

LIBERALISMO: s. m. Polít.: profesion de doctrinas liberales, favorables a las libertades políticas.

La entrada de la voz liberalismo en el $D R A E$ se efectúa, finalmente, en la 11. a edición de 1869 , en que se deja entrever la realidad extralingüística en pleno Sexenio Democrático y un año después de que se hubiera producido la Revolución liberal' 9 .

LIBERALISMO. m. El órden de ideas que profesan los partidarios del sistema liberal. ॥ El partido ó comunion política que entre sí forman.

\subsection{El tratamiento de las voces nación, nacional, nacionalidad y nacionalismo en la lexicografía decimonónica}

Debido a la fuerte influencia del Diccionario de autoridades hasta bien entrado el siglo XIX, era de esperar que la cuarta edición del $D R A E$ (1803) mantuviese las acepciones y su orden establecido desde la primera obra académica. Como se puede observar a continuación, la acepción principal del término nación hace referencia a 'El acto de nacer' y, solo en su segunda acepción, al sentido metonímico de 'La colección de los habitadores en alguna pro-

8 La entrada de la voz liberalidad, a la cual remite la voz liberalismo en su primera acepción, no recoge ningún sentido relacionado directamente con el pensamiento o el sistema político.

9 No se altera la cuarta acepción de liberal introducida en la $10 .^{\mathrm{a}}$ edición del DRAE de 1852. 
vincia, país, ó reyno’. El sentido más sentimental de la palabra se refleja en la entrada de la voz nacionalidad, definida como la 'Afección particular de alguna nación, ó propiedad de ella':

NACION. s. f. El acto de nacer. En este sentido se usa en el modo de hablar de NACION, en lugar de nacimiento; y así dicen: ciego de NACION. Nativitas.

NACION. La coleccion de los habitadores en alguna provincia, pais, ó reyno. Natio, gens. NACION. bax. Se usa freqüentemente en singular para significar qualquier extranjero. Exter gentis homo.

DE NACION. mod. adv. Con que se da á entender la naturaleza de alguno, ó de donde es natural.

NACIONAL. adj. Lo que es propio de alguna nacion, ó pertenece á ella. Gentilitius, nationalis.

CONCILIA NACIONAL. El que se celebra por los prelados de varias provincias, sujetas á un soberano. Concilium nationale.

NACIONALIDAD. $s$. f. Afeccion particular de alguna nacion, ó propiedad de ella. Affectus patrius, nationis propietas.

NACIONALMENTE. adv. m. Con la propiedad, ó costumbre de alguna nacion. More patrio.

No se producen grandes cambios en las siguientes ediciones del DRAE anteriores a la publicación de los diccionarios enciclopédicos y no académicos de mediados del siglo. Donde sí se aprecia una primera adición sustancial al concepto de nación es en la obra de Salvá (1846). Acerca de esta, es preciso recordar las palabras del lexicógrafo por lo que a las voces dialectales atañe:

Si el andaluz, aragonés, extremeño, manchego, murciano, riojano, etc. ven figurar en el Diccionario sus modismos, sus árboles y plantas más comunes, y la nomenclatura más generalizada de sus labores del campo y de sus artes y oficios; es una notoria injusticia que el chileno, filipino, granadino, guatemalteco, habanero, mejicano, peruano, venezolano, etc. no encuentren en él sus provincialismos, los frutos del campo que forman su principal sustento, de las plantas y árboles que les son más conocidos, las palabras que emplean en su agricultura y artefactos, y sobre todo en el beneficio de las minas de oro y plata ("Introducción del Adicionador", p. 14)

Sin que en el prólogo deje constancia explícita de ello, el Adicionador no solo añade entradas lexicográficas enteras, sino que también recoge alguna acepción propia de las hablas de América bajo los lemas ya existentes en la macroestructura de la 9. ${ }^{a}$ edición del DRAE de 1843. Y este es el caso de la acepción neológica en el artículo de la voz nación, en que recoge el uso americano de la voz como "conjunto de indios que hablan la misma lengua con corta diferencia, sean pocos ó muchos, y bien estén juntos, bien derramados en distintas rancherías." (Salvá 1846, s.v. nación).

[|| En América se entiende generalmente por NACION conjunto de indios que hablan la misma lengua con corta diferencia, sean pocos ó muchos, y bien estén juntos, bien derramados en distintas rancherías. 
Aun así, no es el primero en documentar y sugerir la relación intrínseca de una nación con una lengua determinada, sino que esta misma acepción ya aparece unos 60 años antes en el diccionario de Terreros y Pando (1786-93), quien describe, bajo el lema complejo nación diversa, que así "llaman en Californias á la que usa de diverso lenguaje sin necesitarse otra circunstancia como en otras partes, en que se juzga diversa nación la que corresponde á diverso dominio: no obstante, también toman en Californias algunas veces el nombre de diversa nacion, no tanto de la lengua como del paraje en que vive, ó de otras semejantes circunstancias."

NaCion diversa, llaman en Californias á la que usa de diverso lenguaje sin necesitarse otra circunstancia como en otras partes, en que se juzga diversa nacion la que corresponde á diverso dominio: no obstante, también toman en Californias algunas veces el nombre de diversa nacion, no tanto de la lengua como del paraje en que viven, ó de otras semejantes circunstancias.

La segunda adición de Salvá (1846) que resulta de gran interés se recoge bajo el lema de nacionalidad, que es definida -en una segunda acepción que complementa la que se ha mantenido invariable desde Autoridades y vincula por primera vez los conceptos de nación y pueblo a partir de una reflexión política- como "El estado de los pueblos que forman una nación independiente".

NACIONALIDAD. $\mathrm{f}$. Afeccion particular de alguna nacion ó propiedad de ella. Affectus patrius, nationis propietas. [|| neol. El estado de los pueblos que forman una nacion independiente.]

Por lo que se refiere al diccionario de Domínguez (1846-47), es preciso resaltar que ya el propio nombre de la obra, Diccionario nacional ${ }^{10}$, hace referencia explícita al concepto objeto de nuestro estudio. Asimismo, se recoge la idea de nación en el "Prólogo del autor" (p. 2): "He aquí la razon de ese cambio que de una generacion á otra se observa en los usos, en las costumbres y en el lenguage de una misma nacion, de una misma provincia, de un mismo pueblo."

Esta idea que -por lo que podemos deducir de estas palabras- considera la nación como un conjunto de personas que comparte usos, costumbres y lengua, también se refleja en el artículo lexicográfico correspondiente, en que recoge, aparte de la primera acepción referida al 'nacimiento', las siguientes definiciones (Domínguez 1846-47, s. v. nación):

Nacion, s. f. Conjunto ó aglomeración de todos los habitantes de un país, ya esten recogidos por unas mismas leyes, ya reconozcan diferentes formas de gobierno, los cuales generalmente tienen un idioma comun, que los distingue y caracteriza \| Reunion ó conjunto de hombre que tienen un mismo orijen; así se dice: la nacion judia, la nacion eslava, etc.

Un último aspecto reseñable se encuentra bajo la voz nacionalidad, ya que Domínguez es el primero en documentar, entre otros, lexicográficamente el uso administrativo (Domínguez 1846-47, s. v. nacionalidad):

10 Este nombre se debe a su influencia francesa, concretamente al Dictionnaire national ou gran dictionnaire critique de la langue française (Bescherelle 1843). 
Nacionalidad, s. m. Condición ó estado de una persona que pertenece á tal cual nacion, sea por nacimiento, sea por asociacion, ó sea porque ha adquirido en ella carta de naturaleza. || Espíritu de union y de confraternidad que existe entre los habitantes de una nacion.

Posterior a Domínguez, es el diccionario de Gaspar y Roig (1855) la primera obra en documentar la voz nacionalismo, aunque desde un punto de vista exclusivamente sentimental, y no político (s. v. nacionalismo):

NACIONALISMO: s. m.: el afecto e inclinacion de los habitantes de un pais a su propia patria y a todo lo que la pertenece.

Quisiéramos recordar aquí las palabras del prólogo del $D R A E 1869$ citadas en 3.2., en que la Academia afirma que se ha mantenido firme en su decisión de no sancionar más palabras nuevas que las indispensables, dado que el diccionario en cuestión da entrada a nuevas acepciones a las palabras nación, nacional y nacionalidad y recoge, por primera vez, la voz nacionalismo en la macroestructura (DRAE 1869, s. v. nación, nacionalidad y nacionalismo $)^{11}$ :

NACION. f. El estado ó cuerpo político que reconoce un centro comun supremo de gobierno. || Se dice también hablando del territorio que comprende, y áun de sus individuos, tomado colectivamente.

NACIONAL. $\mathrm{m}$. El individuo de la milicia de este nombre.

NACIONALIDAD. $\mathrm{f}$. La condicion y carácter peculiar de la agrupación de pueblos que forman un Estado independiente. || La que adquieren los individuos de pertenencer á una nacion determinada, ó por haber nacido en ella, ó á consecuencia de la naturalizacion.

NACIONALISMO. M. El apego de los naturales de una nacion á ella propia y á cuanto le pertenece.

No solo podemos observar como la RAE trata la voz nación con el sentido geopolítico moderno (sin incluir la lengua común como rasgo distintivo), sino que queda patente que una nueva acepción de la voz nación, además la primera, se corresponde con la acepción neológica de Domínguez (y que no se contempla en Gaspar y Roig). En cuanto a la voz nacionalidad, recoge los dos sentidos administrativos que Domínguez combina bajo una sola acepción y prescinde del sentido más sentimental. En cambio, cabe comentar que la entrada nacionalismo recoge el sentido más sentimental como única acepción.

El cambio más destacado que introduce el DRAE 1884 acerca de las voces estudiadas atañe a la voz nación, dado que se efectúa un cambio de orden de acepciones - el uso etimológico de nacimiento, además de recibir la marca lexicográfica fam., es relegado detrás de las acepciones políticas (DRAE 1884, s. v. nación):

NACION. (Del lat. naťoo.) f. Estado ó cuerpo político que reconoce un centro común supremo de gobierno. || Territorio que comprende, y aun sus individuos, tomados colectivamente. || Conjunto de los habitadores en una provincia, país ó reino. || El mismo país o reino. $\|$ fam. Nacimiento [...].

11 Solo reproducimos las acepciones y entradas neológicas. 


\subsection{El tratamiento de la voz nacionalismo más allá de la lexicografía decimonónica}

Sin proponernos un análisis exhaustivo de todos los matices de estas voces más allá de la lexicografía del siglo XIX, no nos parece baladí esbozar el origen diccionarístico de las dos acepciones de la voz nacionalismo que recoge el $D E L$ :

\section{nacionalismo}

1. m. Sentimiento fervoroso de pertenencia a una nación y de identificación con su realidad y con su historia.

2. m. Ideología de un pueblo que, afirmando su naturaleza de nación, aspira constituirse como Estado.

La segunda de estas dos acepciones, que es la que se refiere al nacionalismo de las naciones sin Estado propio, nace en plena Primera Guerra Mundial, en el Diccionario de la Lengua Española de Alemany y Bolufer (1917, s. v. nacionalismo) ${ }^{12}$ :

NACIONALISMO. (de nacional). m. Apego de los naturales de una nación a ella propia y a cuanto le pertenece. || Doctrina de las reivindicaciones políticas de las nacionalidades oprimidas. Nacionalismo polaco. || Partido que considera mala toda doctrina cuyo fundamento no sea la tradición nacional. || Conjunto de todos los nacionalistas.

Por último, la segunda acepción que se recoge en el $D E L$ se remonta a la época de la dictadura de Primo de Rivera y, lexicográficamente hablando, al DRAE 1925, en que se encuentra la siguiente definición de la voz nacionalismo ${ }^{13}$ :

NACIONALISMO. 2. Doctrina que exalta en todos los órdenes la personalidad nacional completa, o lo que reputan como tal los partidarios de ella.

\section{CONCLUSIONES}

Queremos confirmar, en primer lugar, que las corrientes lingüísticas y, como productos de ellas, las obras lexicográficas, no pueden estudiarse sin tener en cuenta la realidad sociopolítica e ideológica contemporánea, sobre todo cuando se trata de épocas y estadios anteriores a los principios positivistas y empiristas actuales. Prueba de ello, lo demuestra el tratamiento que la lexicografía académica da a voces políticas y hasta cierto punto ideologizadas durante toda la primera mitad del siglo XIX, frente a la acogida diferente y más abierta a innovaciones que proporciona la lexicografía no académica y más liberal de la misma época. Y es que la Real Academia Española muestra más inmovilismo y más conservadurismo que las obras no académicas contemporáneas, por lo que al vocabulario, tanto del liberalismo como el del nacionalismo, las dos grandes ideologías políticas nacidas durante la primera mitad del siglo XIX, se refiere.

Los grandes cambios que se producen finalmente también en el tratamiento que reciben las voces pertenecientes a los campos de lo liberal y lo nacional en el DRAE 1869, y que no

12 Es de especial interés el ejemplo del nacionalismo polaco, ya que justo un año después de la publicación de este diccionario, Polonia iba a recuperar su independencia de Alemania y Prusia.

13 Las dos acepciones actuales se juntan por primera vez en el DRAE 1970. 
son meramente técnicas, podrían tener una triple justificación: por un lado, la publicación de los diccionarios enciclopédicos no académicos confeccionados por espíritus liberales, algunos incluso desde el exilio, y que dan entrada a acepciones que se refieren a ideas políticas nuevas y reflejan el zeitgeist de mediados del siglo XIX; por otro, los enormes cambios políticos y sociales que se produjeron durante todo el siglo XIX, pero, sobre todo, a partir de la Revolución de 1868 y el inicio del Sexenio Democrático. Por último, estas fechas señaladas en clave política coinciden, asimismo, con las periodizaciones propuestas, dado que es la duodécima edición de 1884 la que consolida el cambio iniciado en el DRAE 1869, como hemos podido observar particularmente en el tratamiento de la voz nación.

\section{REFERENCIAS BIBLIOGRÁFICAS}

Alemany y Bolufer (1917): Diccionario de la Lengua Española. Barcelona: Sopena.

Alvar Ezquerra, M. (1987 [2002]): "El diccionario de Terreros". En Terreros y Pando, E.: Diccionario castellano con las voces de las ciencias y artes y sus correspondencias en las tres lenguas francesa, latina e italiana, 4 vols. Madrid: Arco/Libros. [Citado por De antiguos y nuevos diccionarios del español. Madrid: Arco/Libros, 2002, pp. 287-303].

Alvar Ezquerra, M. (2002): De antiguos y nuevos diccionarios del español. Madrid: Arco/Libros.

Álvarez de Miranda, P. (1992): "En torno al Diccionario de Terreros", Bulletin Hispanique, 94, pp. 559-572.

Álvarez de Miranda, P. (2002): "En torno al Nuevo diccionario de la lengua castellana (1846-47) de Vicente Salvá". En Echenique, M. T. y J. Sánchez Méndez (eds.). Actas del V Congreso Internacional de Historia de la Lengua Española. Valencia, 31 de enero-4 de febrero de 2000, II, Madrid: Gredos, pp. 1875-1886.

Álvarez de Miranda, P. (2003): "Vicente Salvá, editor y corrector del Diccionario de la Academia (1838 y 1841)". En Lexicografía y lexicología en Europa y América. Homenaje a Günther Haensch en su 80 aniversario. Madrid: Gredos, pp. 99-114.

Álvarez Junco, J. (2001): Mater dolorosa. La idea de España en el siglo XIX. Barcelona: Taurus.

Anglada, E. y M. Bargalló (1992): "Principios de lexicografía moderna en diccionarios del siglo XIX". En Ariza, M.(coord.). Actas del II Congreso Internacional de Historia de la Lengua Española, I. Madrid: Pabellón de España, pp. 955-962.

Azorín, D. (1992): "El Diccionario General de la Lengua frente a los vocabularios científicos y técnicos”. En Euralex'90 Proceedings: IV International Congress. Actas de IV congreso internacional. Barcelona: Bibliograf, pp. 445-453.

Azorín, D. y R. Baquero Mesa (1994-95): "De la teoría a la práctica lexicográfica: el Nuevo diccionario de la lengua castellana (1846) de Vicente Salvá", Estudios de lingüistica de la Universidad de Alicante, 10, pp. 9-20.

Azorín, D. (1996-1997): "La lexicografía española en el siglo XIX: del diccionario a la enciclopedia", Estudios de Lingüistica de la Universidad de Alicante, 11, pp.111-122.

Azorín, D. (2000): Los diccionarios del español en su perspectiva histórica. Alicante: Publicaciones de la Universidad de Alicante.

Azorín, D. (2001): "Salvá y la Academia Española: dos posturas frente a la recepción de los tecnicismos en el diccionario de la lengua”. En Esparza Torres, M. Á., B. Fernández Salgado y H. J. Niederehe (eds.). Estudios de Historiografia Lingüistica. Actas del III Congreso de la Sociedad Española de Historiografía Lingüística. Vigo, 7-10 de febrero de 2001, II, Hamburgo: Helmut Buske, pp. 777-788.

Azorín, D. (2003): "Un proyecto original en la lexicografía española del siglo XIX: el Nuevo diccionario de la lengua castellana (1846) de Vicente Salvá". En Lexicografía y lexicología en Europa y América. Homenaje a Günther Haensch en su 80 aniversario. Madrid: Gredos, pp. 115-131. 
Azorín, D. y M. I. Santamaría (2004): "El Diccionario de autoridades (1726-1739) y el Diccionario castellano (1786-1793) de Terreros y Pando ante la recepción de las voces de especialidad", Revista de Investigación Lingüística, 7, pp. 49-69.

Azorín, D. (2009): "Originalidad y trascendencia del Diccionario castellano con las voces de ciencias $y$ artes de Esteban de Terreros y Pando", Revista Internacional de Lingüistica Iberoamericana, 13, pp. 41-62.

Battaner, P. (2008): “La Real Academia Española en las Cortes de Cádiz (1810-1814)”, Boletín de la Real Academia Española, 88, pp. 5-32.

Battaner, P. (2009): "Ecos lingüísticos de la época en los diarios de sesiones de las Cortes gaditanas". En García Martín, J. M. (dir.). Las ideas y realidades lingüisticas en los siglos XVII y XIX. Cádiz: Universidad de Cádiz, pp.13-50.

Bescherelle, L. N. (1843): Dictionnaire national ou gran dictionnaire critique de la langue française. París: Garnier.

Blecua, J. M. (2018): "Presentación”. En Clavería, G. y M. Freixas (coords.). El diccionario de la Academia en el siglo XIX: la quinta edición (1817) al microscopio. Madrid: Arco/Libros, pp. 9-11.

Castro y Rossi, Adolfo de (1852): Gran diccionario de la lengua española. Madrid: Semanario Pintoresco y de La Ilustración.

Carr, R. (19884): España 1808-1975. Barcelona, Ariel.

Carvajal, M. T. (1988): "Tratamiento de los préstamos franceses en los diccionarios españoles del siglo XVIII: el académico de 1780 y el de P. Terreros", Analecta Malacitana, 11, pp. 219-232.

Clavería, G. (2010): "Voces nuevas y neologismo: la contribución de Esteban de Terreros". En Encinas, M. T. et alii (eds.). Ars Longa. Diez años de AJIHLE. Buenos Aires: Voces del Sur, I, pp. 215-236.

Clavería, G. (2016): De vacunar a presupuestar: la lexicografía académica decimonónica y el neologismo. Madrid/Frankfurt: Iberoamericana/Vervuert.

Clavería, G. (2018): "La quinta edición del Diccionario de la lengua castellana (1817) de la Real Academia Española al microscopio". En Clavería, G. y M. Freixas (coords.). El diccionario de la Academia en el siglo XIX: la quinta edición (1817) al microscopio. Madrid: Arco/Libros, pp. 15-55.

Clavería, G. y M. Freixas (coords.) (2018): El diccionario de la Academia en el siglo XIX: la quinta edición (1817) al microscopio. Madrid: Arco/Libros.

Comide Ferrand, E. (2003): La revolución francesa y sus consecuencias para España. A Coruña: Fundación Caixa Galicia.

Domínguez, R. J. (1846-47): Diccionario nacional o gran diccionario clásico de la lengua española. Madrid: Bernat.

Esparza Torres, M. Á. (1999): "Notas sobre el Diccionario Nacional de Ramón Joaquín Domínguez". En Henríquez Salido, M. C. y M. Á. Esparza Torres (eds.). Estudios de historiografía lingüística ofrecidos a Hans-Josef Niederehe. Vigo: Universidad de Vigo, pp. 39-64.

Fernández Sebastián, J. (2009) (dir.): Diccionario politico y social del mundo iberoamericano. La era de las revoluciones, 1750-1850. Iberconceptos I. Madrid: Fundación Carolina.

Fontana J. y R. Villares (dirs.) (2007): La época del liberalismo. Barcelona: Crítica/Marcial Pons.

Fusi, J. P. y J. Palafox (1997): España: 1808-1996. El desafio de la modernidad. Madrid: Espasa.

Gutiérrez Cuadrado, J. (2011): "Ideología y lexicografía". En San Vicente, F. et alii (coords.). IDEOLEX. Estudios de lexicografia e ideología, Monza: Polimétrica, pp. 25-66.

Chao, E. (coord.) (1853-1855): Biblioteca Ilustrada de Gaspar y Roig. Diccionario enciclopédico de la lengua española. Madrid: Gaspar y Roig.

García de Enterría, E. (2001): La lengua de los derechos. La formación del derecho público europeo tras la Revolución Francesa, Madrid: Alianza Editorial.

García Platero, J. M. (2003): "La lexicografía no académica en los siglos XVIII y XIX". En Medina, A. M. (coord.). Lexicografía española. Barcelona: Ariel, pp. 263-306.

García de la Concha, V. (2014): La Real Academia Española. Vida e historia. Madrid: Espasa-Calpe. 
Henríquez Salido, María do Carmo (2009): "Las ideas de democracia, igualdad, justicia y libertad en el Primer diccionario general etimológico de la lengua española de Roque Bárcia". En García Martín, J. M. (dir.). Las ideas y realidades lingüisticas en los siglos XVII y XIX. Cádiz: Universidad de Cádiz, pp. 361-378.

Jiménez Ríos, E. (1996): "El diccionario de Terreros y las primeras ediciones del Diccionario de la Academia". En Alonso, A. (coord.). Actas del III Congreso Internacional de Historia de la Lengua Española. Madrid: Arco/Libros, II, pp. 1357-1370.

Linz, J. J. (1992). "Los nacionalismos en España: Una perspectiva comparada”, Historia y Fuente Oral, pp. 127-135.

Lleal, C. (2015): “Ideología lingüística y lexicografía”, Lletres Asturianes, 113, pp. 27-44.

Martínez Marín, J. (2000): "La lexicografía monolingüe del español en el siglo XIX: la corriente no académica". En Ahumada, I. (ed.). Cinco siglos de lexicografía del español. IV Seminario de Lexicografia Hispánica. Jaén: Universidad de Jaén, pp. 63-77.

Merino, J. M. (2013): "De afrancesados a patriotas en la Real Academia Española”. En Sánchez Ron, J. M. y C. Iglesias (coords.). La lengua y la palabra: trescientos años de la Real Academia Española. Madrid: Real Academia Española, pp. 81-88.

Moreno Moreno, $M^{\mathrm{a}}$. Á. (2009): "La recepción del vocabulario de los primeros liberales en la lexicografía académica decimonónica”. En García Martín, J. M. (dir.). Las ideas y realidades lingüísticas en los siglos XVII y XIX. Cádiz: Universidad de Cádiz, pp. 467-482.

Niederehe, H. J. (2001): "La gramaticografía del siglo XVIII, entre tradición y reorientación”. En Koerner, E. F. K. y H. J. Niederehe (eds.). History of Linguistics in Spain, II, pp. 181-194.

Núñez de Taboada (1825): Diccionario de la lengua castellana. París: Seguin.

Núñez Seixas, X. M. (1993): Historiographical Approaches to Nationalism in Spain. Saarbrücken: Breitenbach.

Pérez Garzón, J. S. (1978): Milicia Nacional y Revolución Burguesa. Madrid: CSIC.

Quilis Merín, M. (2008): "Lenguas y dialectos peninsulares y su normalización en la antigua lexicografía española”, Península. Revista de Estudios Ibéricos, 5, pp. 185-199.

Quilis Merín, M. (2014): “Ideología en el Diccionario Nacional (1846-47) de Ramón Joaquín Domínguez. La "nomenclatura vergonzante”", Boletín Hispánico Helvético, 23, pp. 141-164.

Quilis Merín, M. (2016): "La lexicografía española del siglo XIX: una perspectiva historiográfica". En Salvador Plans, A. et alii (eds.). La historiografía lingüistica como paradigma de investigación. Madrid: Visor Libros, pp. 45-78.

Raab, M. (2018). "La lexicografía no académica y la quinta edición del DRAE”. En Clavería, G. y M. Freixas (coords.), pp. 529-542.

Real Academia Española (1726-1739): Diccionario de la lengua castellana, en que se explica el verdadero sentido de las voces, su naturaleza y calidad con las phrases o modos de hablar, los proverbios o refranes, y otras cosas convenientes al uso de la lengua. 6 vols. Madrid: Imprenta Francisco del Hierro.

Real Academia Española (1803): Diccionario de la lengua castellana, reducido a un solo tomo para su más fácil uso, cuarta edición. Madrid: Viuda de don Joaquín Ibarra. (DRAE 1803)

Real Academia Española (1817): Diccionario de la lengua castellana, quinta edición. Madrid: Imprenta Real. (DRAE 1817)

Real Academia Española (1822): Diccionario de la lengua castellana, sexta edición. Madrid: Imprenta Nacional. (DRAE 1822)

Real Academia Española (1832): Diccionario de la lengua castellana, séptima edición. Madrid: Imprenta Real. (DRAE 1832)

Real Academia Española (1837): Diccionario de la lengua castellana, octava edición. Madrid: Imprenta Nacional. (DRAE 1837)

Real Academia Española (1843): Diccionario de la lengua castellana, novena edición. Madrid: Imprenta de D. Francisco María Fernández. (DRAE 1843) 
Real Academia Española (1852): Diccionario de la lengua castellana, décima edición. Madrid: Imprenta Nacional. (DRAE 1852)

Real Academia Española (1869): Diccionario de la lengua castellana, undécima edición. Madrid: Imprenta de Don Manuel Rivadeneyra. (DRAE 1869)

Real Academia Española (1884): Diccionario de la lengua castellana, duodécima edición. Madrid: Imprenta de D. Gregorio Hernando. (DRAE 1884)

Real Academia Española (1899): Diccionario de la lengua castellana, décimatercia edición. Madrid: Imprenta de los Sres. Hernando y compañía. (DRAE 1899)

Real Academia Española (1925): Diccionario de la lengua española, décima quinta edición. Madrid: Calpe. (DRAE 1925)

Real Academia Española (1970): Diccionario de la lengua española, decimonovena edición. Madrid: Calpe. (DRAE 1970)

Real Academia Española y Asociación de Academias de la Lengua Española (2014): Diccionario de la lengua española, vigesimotercera edición. Madrid: Espasa. (DLE)

Real Academia Española (2001): Nuevo tesoro lexicográfico de la lengua española, edición en DVD. Madrid: Espasa. [También en línea $<$ http://ntlle.rae.es>]. (NTLLE)

Reig Salvá, C. (1972): Vicente Salvá. Un valenciano de prestigio internacional. Valencia: Instituto Alfonso el Magnánimo.

Salvá, V. (1846): Nuevo diccionario de la lengua castellana. París: Fournier.

Seco, M. (1983): "La definición lexicográfica subjetiva: el Diccionario de Domínguez". En Serta philologica F. Lázaro Carreter natalem diem sexagesimum celebranti dicata, I. Madrid: Cátedra, pp. 587-596.

Seco, M. (1987): "El nacimiento de la lexicografía moderna no académica”, Estudios de lexicografía española. Madrid: Paraninfo, pp. 129-151.

Terreros y Pando. E. (1786-93): Diccionario castellano con las voces de ciencias y artes y sus correspondientes en las tres lenguas francesa, latina e italiana. Madrid: Viuda de Ibarra (Edición facsímil con "Presentación" de M. Alvar Ezquerra [1987: Madrid: Arco/Libros]).

Vázquez, I. (2006): Lexicografía bilingüe hispano-lusa: Mascarenhas Valdez. Tesis doctoral. Barcelona: Universidad de Barcelona.

Zamora Vicente, A. (1999): Historia de la Real Academia Española. Madrid: Espasa. 